$$
\begin{aligned}
& \text { SAN097-3181C } \\
& \text { SAND- } 97-3 / 81 C
\end{aligned}
$$

\title{
Using Corresponding State Theory to Obtain Intermolecular Potentials to Calculate Pure Liquid Shock Hugoniots \\ (U) $1 F=980804--$
}

\author{
Michael L. Hobbs* \\ Engineering Sciences Center, 9100 \\ Sandia National Laboratories, \\ Albuquerque, New Mexico 87185
}$$
\text { CDNF- } 98080
$$

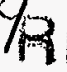$$
\text { DEC } 291997 \text {. }
$$$$
\text { O Sm }
$$

\section{ABSTRACT}

Determination of product species, equations-of-state (EOS) and thermochemical properties of high explosives and pyrotechnics remains a major unsolved problem. Although, empirical EOS models may be calibrated to replicate detonation conditions within experimental variability (5-10\%), different states, e.g. expansion, may produce significant discrepancy with data if the basic form of the EOS model is incorrect. A more physically realistic EOS model based on intermolecular potentials, such as the Jacobs Cowperthwaite Zwisler (JCZ3) EOS [1], is needed to predict detonation states as well as expanded states.

Predictive capability for any EOS requires a large species data base composed of a wide variety of elements. Unfortunately, only 20 species have known JCZ3 molecular force constants. Of these 20 species, only 10 have been adequately compared to experimental data such as molecular scattering or shock Hugoniot data. Since data in the strongly repulsive region of the molecular potential is limited, alternative methods must be found to deduce force constants for a larger number of species. The objective of the present study is to determine JCZ3 product species force constants by using a corresponding states theory.

Intermolecular potential parameters were obtained for a variety of gas species using a simple corresponding states technique with critical volume and critical temperature. A more complex, four parameter corresponding state method with shape and polarity corrections was also used to obtain intermolecular potential parameters. Both corresponding state methods were used to predict shock Hugoniot data obtained from pure liquids. The simple corresponding state method is shown to give adequate agreement with shock Hugoniot data.

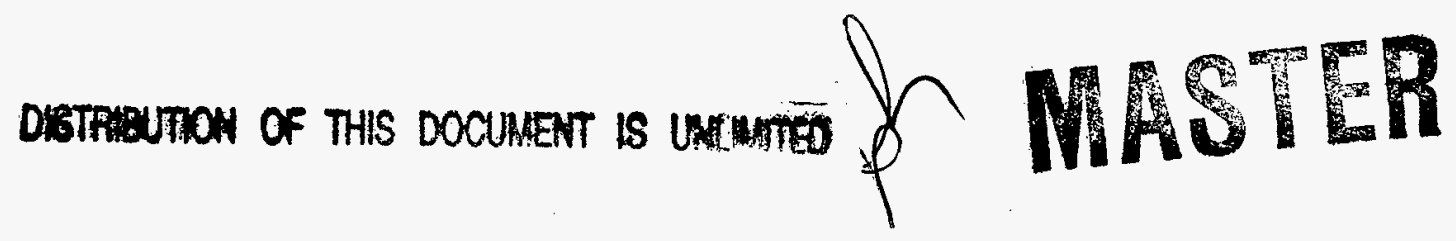

* This work performed at Sandia National Laboratories. Sandia is a multiprogram laboratory operated by Sandia Corporation, a Lockheed Martin Company, for the U.S. Department of Energy under contract DEACO4-94AL85000 


\section{DISCLAIMER}

This report was prepared as an account of work sponsored by an agency of the United States Government. Neither the United States Government nor any agency thereof, nor any of their employees, makes any warranty, express or implied, or assumes any legal liability or responsibility for the accuracy, completeness, or usefulness of any information, apparatus, product, or process disclosed, or represents that its use would not infringe privately owned rights. Reference herein to any specific commercial product, process, or service by trade name, trademark, manufacturer, or otherwise does not necessarily constitute or imply its endorsement, recommendation, or favoring by the United States Government or any agency thereof. The views and opinions of authors expressed herein do not necessarily state or reflect those of the United States Government or any agency thereof. 


\section{INTRODUCTION}

Predictive capability for any EOS requires a large species data base composed of a wide variety of elements. Unfortunately, only 20 species have known JCZ3 molecular force constants. Of these 20 species, only 10 have been adequately compared to experimental data such as molecular scattering or shock Hugoniot data. The thermochemical properties of pyrotechnics are difficult to calculate at high pressures due to complex compositions which produce various condensed-phases. For example, 33 gas-phase species and 24 condensed-phase species composed of $\mathrm{Al}, \mathrm{Cl}, \mathrm{K}, \mathrm{O}$, or Ti, typical components in a report charge $(\mathrm{Ti} / \mathrm{Al} / \mathrm{KClO} 4)$, have been used with the empirical BKWS-EOS [2] to calculate detonation states. An overview of detonation physics is found in Ref. [3].

JCZ3-EOS - The JCZ3-EOS uses an equation based on P-V-T relationships similar to the Mie-Grüneisen EOS [4]

$$
P=\frac{G(V, T) n R T}{V}+P_{0}(V)
$$

where $P, n, R, T$, and $V$ represent the pressure, number of moles, universal gas constant, and volume, respectively. The form of the Grüneisen function, $G$, and the volume dependent internal pressure function, $P_{0}$, is documented (e.g., Ref. 1). The volume-dependent internal pressure function, $P_{o}(V)$ is composed of the exponential 6 potential function:

$$
\varphi(r)=\varepsilon\left[\left(\frac{6}{\eta-6}\right) \exp \left[\eta\left(1-r / r^{*}\right)\right]-\left(\frac{\eta}{\eta-6}\right)\left(\frac{r}{r}\right)^{*}\right]
$$

where $\varepsilon$ is the well depth for the pair potential and $r^{*}$ is the radius of the minimum pair potential energy. The molecular force parameters $\varepsilon, \eta$, and $r^{*}$ are required for each product species. The force constant, $\varepsilon$, is often given as $\varepsilon / k$, where $k$ is Boltzmann's constant.

Corresponding States Methods - The idea of the corresponding states method as originally proposed by van der Waals [5] is that the behavior of all substances is the same at the same reduced temperature $\left(T / T_{c}\right)$, pressure $\left(P / P_{c}\right)$, and volume $\left(V / V_{c}\right)$. Pitzer [6] derived van der Waals' corresponding states principle by assuming 1 ) classical statistics, 2) spherically symmetric nonpolar molecules, 3) similar molecular vibrations for both liquid and gaseous states, and 4) conformal molecules. The conformal assumption implies that the functionality of the intermolecular potential is the same although the force constants vary from molecule-to-molecule.

The corresponding states method can be applied with confidence to molecules which comply to Pitzer's assumptions. These molecules include the heavier rare gases such as Argon, Krypton, and Xenon as well as spherically symmetric molecules such as methane. Hydrogen, Helium, and Neon do not follow corresponding states because of quantum effects [7].

Pitzer's Deviation - Deviations from corresponding states estimates were determined by Hougen and Watson [8] to range from 5 to $35 \%$. These deviations result from molecules which are not perfectly spherical or nonpolar. To improve corresponding states estimates for molecules which are not perfectly spherical, Pitzer and coworkers [7,9], introduced the acentric factor, $\omega$, to account for deviations from spherical molecules:

$$
\omega=-\log P_{r}-1.000
$$


where the reduced pressure, $P_{r}$ is evaluated at a reduced temperature, $T_{n}$ of 0.7 . The form of Eq. (3) was chosen since the reduced vapor pressure is almost precisely 0.1 at the reduced temperature of 0.7 for corresponding molecules $\mathrm{Ar}, \mathrm{Kr}, \mathrm{Xe}$, and $\mathrm{CH}_{4}$, giving an $\omega$ of essentially zero for these molecules.

Pitzer et al. [7,9] chose to expand the compressibility factor function as a power series in the acentric factor

$$
z=z_{o}+\omega z_{1}+\ldots
$$

where $z_{o}, z_{1}$, etc. are each functions of $T_{r}$ and $P_{r}$ giving a three parameter corresponding states equation to predict compressibility. This approach improved predictions over simple corresponding state theory for nonspherical molecules [7]. Pitzer et al. [7,9] concluded that a three parameter corresponding state theory is inadequate for highly polar molecules such as water or ammonia. A fourth parameter is necessary for accurate corresponding state correlation.

Lee and Kesler's Improvements - Lee and Kesler improved Pitzer's corresponding states model given in Eq. (4) using a Taylor's series expansion about the simple fluid with respect to the acentricity factor:

$$
z=z_{o}+\frac{\omega}{\omega_{r}}\left(z_{r}-z_{o}\right)
$$

where the subscripts $o$ and $r$ refer to a simple reference fluid with an acentric factor of zero and a heavy reference fluid, respectively. The data used to determine the constants for the simple fluid were principally $\mathrm{Ar}, \mathrm{Kr}$, and methane. N-octane was chosen as the heavy reference fluid. The Lee-Kesler (LK) model is useful for predicting the thermodynamic properties of nonpolar and slightly polar fluids. The success of the LK corresponding states method is due to the accurate analytic equation of state which represent the two reference fluids [10]. The LK model is a three parameter corresponding states method in $\omega, T_{c}$, and $P_{c}$.

Extension to Polar Molecules - To predict thermodynamic properties for both polar and nonpolar fluids, Wilding and Rowley [10] extended the LK model to account for both geometric as well as polar contributions. The Extended Lee-Kesler (ELK) model [10] is written as a dimensionless Taylor's series expansion about a simple fluid with respect to geometry and polarity:

$$
J=J_{o}+(\partial J / \partial \alpha)_{T_{r}, P_{r}, \beta}\left(\alpha-\alpha_{o}\right)+(\partial J / \partial \beta)_{T_{r}, P_{r}, \alpha}\left(\beta-\beta_{o}\right)+O\left(\alpha^{2}, \beta^{2}, \alpha \beta\right)
$$

where $J_{o}$ is the simple fluid dimensionless property such as compressibility at the given reduced conditions, $\alpha$ is a size and shape constant, and $\beta$ is a polarity constant. To apply Eq. (6) to an arbitrary molecule, high order terms are assumed negligible and both partial derivatives, the geometric constant, and the polarity constant must be defined. The LK model considers only the first two terms on the right-hand-side of Eq. (6).

The partial derivatives can be determined by using corresponding molecules at the same $T_{r}$ and $P_{r}$ as the test molecule. The partial derivative with respect to shape, $(\partial J / \partial \alpha)_{T_{r}, P_{r}, \beta}$, is determined using argon and $\mathrm{n}$-hexane. In the present study, $\mathrm{n}$-hexane is used instead of n-octane, which was used by Rowley et al. as well as Lee and Kesler, because pure shock Hugoniot data 
needed to deduce force constants is available for $n$-hexane and not for n-octane. The shape partial derivative becomes:

$$
(\partial J / \partial \alpha)_{T_{r}, P_{r}, \beta}=\left(J_{h x}-J_{a r}\right) / \alpha_{h x}
$$

where the subscripts ar and hx refer to argon and n-hexane, respectively. The shape factor for argon is assumed to be zero.

The polar partial derivative can be obtained by using water and a hypothetical molecule which is the same size as water but is nonpolar (i.e. $\beta$ is zero). Since the hypothetical molecule is nonpolar, thermodynamic properties for the hypothetical molecule can be obtained using Eq. (6) or by Eq. (7). The polar partial derivative becomes:

$$
\begin{gathered}
(\partial J / \partial \beta)_{T_{r}, P_{r}, \alpha}=\left(J_{h 2 o}-J_{h y p}\right) / \beta_{h 2 o} \\
J_{h y p}=J_{A r}+\alpha_{h 2 o}\left(J_{h x}-J_{a r}\right) / \alpha_{h x}
\end{gathered}
$$

where the subscripts $h 2 o$ and hyp refer to water and the hypothetical molecule, respectively. Substitution of Equations (7)-(9) into Equation (6) gives the general four-parameter ELK equation applicable to all types of molecules:

$$
J=J_{a r}+\alpha\left(J_{h x}-J_{a r}\right) / \alpha_{h x}+\beta\left\{J_{h 2 o}-\left[J_{A r}+\alpha_{h 2 o}\left(J_{h x}-J_{a r}\right) / \alpha_{h x}\right]\right\} / \beta_{h 2 o}
$$

In summary, the ELK method is a four parameter $\left(T_{c}, P_{c}, \alpha\right.$, and $\left.\beta\right)$ corresponding states technique that uses three well-characterized reference fluids. The first reference fluid is a pure corresponding states fluid (argon), the second fluid is used to correct for geometric effects (hexane), and the third fluid is used to correct for polar effects (water).

The geometrical parameter $\alpha$ must be independent of polarity. Wilding and Rowley [10] based $\alpha$ on the radius of gyration, $r$, a purely geometric quantity available from molecular structure information. The functionality of $\alpha$ is determined by correlating the acentricity factor, $\omega$, for nonpolar fluids with the radius of gyration:

$$
\alpha=-7.706 \times 10^{-4}+0.0330 r+0.01506 r^{2}-9.997 \times 10^{-4} r^{3}
$$

This correlation is applicable to all fluids regardless of polarity and represents only geometrical effects [10]. The value of $\alpha$ is zero for the reference fluid argon.

The polar parameter $\beta$ is obtained by application of Eq. (10) to any known value of $J$. Wilding and Rowley [10] use the liquid density at some $T_{r}$ and $P_{r}$ to determine the compressibility by setting $J$ equal to $Z$ and calculating $\beta$ directly from Eq. (10). The value of $\beta$ for the reference molecule water is set equal to one. For hydrogen bonding molecules, especially alcohols, enthalpic properties are not predicted as well as volumetric properties. For more accuracy, the heat of vaporization, $\Delta H_{v}$, at the normal boiling point can be used to calculate $\beta$ and may give better results. To differentiate between the two methods of calculating the polar parameter $\beta$, a subscript $h$ is used to denote the enthalpic origins: $\beta_{h}$. 


\section{APPLICATION OF ELK TO JCZ3 FORCE CONSTANTS}

The force constants for the JCZ3-EOS can be determined by applying Eq. (10) to the dimensionless force constants as follows:

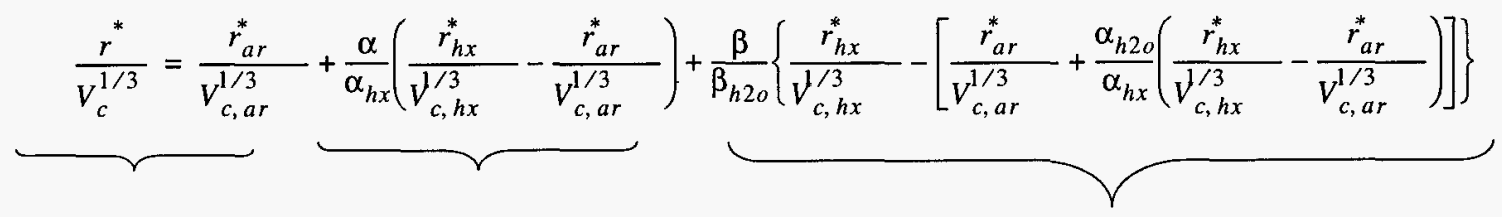

Correspond-

ing States

Shape Corrections

Polar Corrections

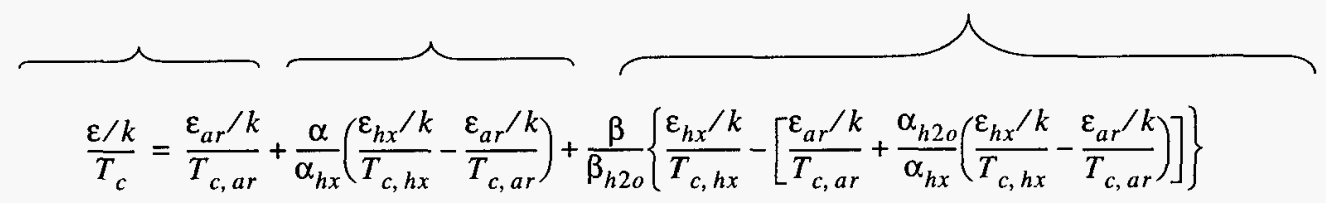

The first terms marked "Corresponding States" of Eq. (12) and (13) represent the simple-corresponding states law used by Ross and Ree [11] to deduce force constants as proposed originally by Hirschfelder et al. [12]. The last two terms on the right hand side of Eq. (12) and (13) represent geometrical deviations and polar deviations, respectively.

Force Constants - Table 1 gives the force constants found in the literature for the JCZEOS. Accurate force constants for argon, n-heptane, and water are needed to apply Eq. (12) and (13). As shown in Table 1, the exponential 6 potential parameters differ significantly between investigators. Pure shock Hugoniots for $\mathrm{Ar}, \mathrm{CH}_{4}, \mathrm{CO}_{2}, \mathrm{H}_{2}, \mathrm{H}_{2} \mathrm{O}, \mathrm{N} 2, \mathrm{NH} 3, \mathrm{O} 2$, and Xe predicted using the JCZ3-EOS as implemented in the CHEETAH code [19] using force constants from Table 1 are compared to measurements in Fig 1. The force constants which fit the Hugoniot data the best are shaded in Table 1 . Note that $\eta$ is 13 for the best fits. Within experimental uncertainty, Ross and Alder [20] indicate that the potential for argon can be fit with any $\eta$ between 12 and 14 with 13 being the best value. This seems to be the case for other molecules as shown in Fig 1. For the present study, $\eta$ is assumed to be 13 for all molecules.

N-hexane Hugoniot - In order to apply Eq. (12) and (13) to any molecule, the force constants for $\mathrm{n}$-hexane need to be determined. Fig 2 shows predicted and measured pure shock Hugoniot for $\mathrm{n}$-hexane. The $\mathrm{n}$-hexane force constants were obtained by using simple-corresponding states theory to obtain $r_{h x}^{*}$, and best fitting $\varepsilon / k$ to data. The value for $r_{h x}^{*}$ and $\varepsilon / k$ were determined to be $6.6 \AA$ and $300 \mathrm{~K}$, respectively.

\section{HUGONIOT CALCULATIONS}

To determine the validity of the ELK method applied to the JCZ3 force constants, Eq. (12) and (13) were applied to various test molecules. The predicted JCZ3 force constants are given in Table 2 using the simple corresponding states method, the ELK method using $\beta$, and the ELK method using $\beta_{h}$. The parameters required for each molecule are given in Table 3. The size and shape parameter, $\alpha$, and the polar parameters $\beta$ and $\beta_{h}$ were obtained from Ref. [32].

Predictions using simple corresponding state theory (SCS) as well as the ELK method are compared to measured Hugoniots in Fig 3 and 4. In general, the predictions using the ELK 
method are better than using the SCS method. The exceptions are dibromomethane, methanol and acetone, although the ELK predictions are in acceptable agreement with the limited set of Hugoniot data available. Only two Hugoniot points are available for methanol and acetone.

The comparison between the predicted and experimental shock Hugoniot data for hexane and water, as shown in Figure 4, show the influence of shape and polar contributions. Shape effects move the Hugoniot curve up, whereas polar effects move the Hugoniot curve down in relation to the experimental data. The agreement with Hugoniot data in these high pressure regimes is promising for increasing the JCZ3-EOS product species database.

\section{CAVEATS}

Unfortunately, not all chemical species have critical properties. Out of 750 gas species listed in the JANNAF tables [33], 150 species have both the critical temperature and critical volume. Thus alternative methods must be used to determine the intermolecular force constants. Hobbs et al. [34, 35] have obtained intermolecular force constants for all 750 gases using a combination of corresponding state theory, pure liquid shock Hugoniot data from the present study, and fit values using an empirical EOS. The large database can be used with the CHEETAH computer program [19] to permit intermolecular potential based calculations of exotic energetic materials of complex elemental composition.

\section{SUMMARY AND CONCLUSION}

Pure shock Hugoniot calculations have been performed with the JCZ3-EOS which is based on the exponential 6 potential function. The radius of the minimum pair potential energy and the well depth of the exponential 6 potential well has been estimated using simple corresponding states methods as well as the ELK corresponding states method. The simple corresponding state method is shown to give adequate agreement with shock Hugoniot data.

\section{ACKNOWLEDGEMENTS}

Mel Baer encouraged development of the database of intermolecular parameters for gasphase species to make the JCZ3-EOS widely applicable to energetic materials. Internal reviewers at Sandia National Laboratories, R. Schmitt and S. Tieszen, are also gratefully acknowledged.

\section{REFERENCES}

1. Cowperthwaite, M. and Zwisler, W. K., Sixth Symposium (International) on Detonation, ACR221, Office of Naval Research, Arlington, VA, 1976, pp 162-172.

2. Hobbs, M. L., Tanaka, K., Iida, M., Matsunaga, T., Proceedings of the Third Beijing International Symposium on Pyrotechnics and Explosives, Beijing, China, 1995, pp 16-21.

3. Fickett, W. and Davis, W. C. Detonation, University of California Press, Berkeley, CA, 1979

4. Jacobs, S. J., "On the Equation of State of Compressed Liquids and Solids," NOLTR 68-214, United States Naval Ordnance Laboratory, White Oak, MD, 1968

5. van der Waals, J. D. Sr., Doctoral Dissertation, Leiden, 1873 
6. Pitzer, K. S., J. of Chem. Phys., 7:583 (1939)

7. Pitzer, K. S., J. Am. Chem. Soc., 77(13):3427 (1955)

8. Hougen O. A., and Watson, K. M., "Chemical Process Principles, Part Two, Thermodynamics," John Wiley and Sons, Inc., New York, New York (1947).

9. Pitzer, K. S., Lippmann, D. Z., Curl, R. F., Jr., Huggins, C. M. and Petersen, D. E., J. Am. Chem. Soc., 77(13):3433 (1955)

10. Wilding, W. V., and Rowley, R. L., Int. J. of Thermophysics, 7(3):525 (1986)

11. Ross, M. and Ree, F. H., J. Chem. Phys. 73(12):6146 (1980)

12. Hirschfelder, J. O., Curtiss, C. F., and Bird, R. B., Molecular Theory of Gases and Liquids, Wiley, New York, 1954, p 234

13. Fickett, W., "Intermolecular Potential Functions for Some Simple Molecules from Available Experimental Data," Los Alamos National Laboratory Report No. LA-2665, TID-4500, 1962

14. Brown, W. B., and Braithwaite, M., Ninth Symposium (International) on Detonation, OCNR 113291-7, Office of Naval Research, Arlington, VA, 1989, pp 513-524.

15. Mader, C. L., Numerical Modeling of Detonations, University of California Press, Los Angeles, 1979

16. Finger, M., Lee, E., Helm, F. H., Hayes, B., Hornig, H., McGuire, R., Kahara, M., and Guidry, M., Sixth Symposium (International) on Detonation, ACR-221, Office of Naval Research, Arlington, VA, 1976, 710-722.

17. Chirat, R. and Pittion-Rossillon, G. Seventh Symposium (International) on Detonation, NSWC MP 82-334, Naval Surface Weapons Center, White Oak, Silver Spring, Maryland, 703 (1981).

18. Ree, F. H., J. Chem. Phys., 81:1251 (1984)

19. Fried, L. E., "CHEETAH 1.39 User's Manual," UCRL-MA-117541 Rev. 3, Energetic Materials Center, Lawrence Livermore National Laboratory, Livermore, California (1994).

20. Ross, M., and Alder, B., J. Chem. Phys., 46(11):4203 (1967)

21. Marsh, S. P., editor, LASL Shock Hugoniot Data, University of California Press, Berkeley, CA, 1980

22. Nellis, W. J. and Mitchell, A. C.,J. Chem. Phys., 73(12):6137 (1980)

23. van Thiel, M. and Alder, B. J., J. Chem. Phys., 44(3):1056 (1966)

24. Nellis, W. J., Ree, F. H., van Thiel, M., Mitchell, A. C., J. Chem. Phys., 75(6):3055 (1981)

25. Zubarev, V. N., Telegin, G. S., Soviet Physics - Doklady, 7 (1), 34 (1962). Data from this paper reduced by Ross and Ree (see Ref. 11).

26. Ree, F. H., J. Chem. Phys., 81:1251 (1984) 
27. Lyzenga, G. A., Ahrens, T. J., Nellis, W. J., and Mitchell, A. C., J. Chem. Phys., 76(12):6282 (1982)

28. Dick, R. D., J. Chem. Phys., 74(7):4053 (1981)

29. Kovel, M. I., "The Shock Wave Hugoniot and Electrical Conductivity of Liquid Ammonia in the Pressure Range $45 \mathrm{~kb}$ to $282 \mathrm{~kb}$," Ph.D. Theses, Lawrence Livermore Laboratory, UCRL51367, University of California, Livermore, CA, 1973.

30. Radousky, H. B., Mitchell, A. C., Nellis, W. J., and Ross, M., "Shock Temperature Measurements in Ammonia," in Shock Waves in Condensed Matter, edited by Gupta, Y. M., Plenum Press, New York (1986).

31. Nellis, W. J., van Thiel, M., and Mitchell, A. C., Physical Review Letters, 48(12):816 (1982)

32. Rowley, R. L., "ELK, Extended Lee-Kesler--A Four-Parameter Corresponding States Method for Prediction of Thermophysical Properties of Pure Fluids and Mixtures," IBM PC compatible software and manual, Dept. of Chem. Eng., Brigham Young University, Provo, Utah (1993).

33. Chase, M. W., Davies, C. A., Downey, J.R., Frurip, D. J., McDonald, R. A., Syverud, A. N., J. of Physic. and Chem. Ref. Data, 14:1-1856 (1985)

34. McGee, B. C., Hobbs, M. L., and Baer, M. R. "Exponential 6 Parameterization for the JCZ3EOS," Sandia National Laboratories Report No. SAND98-\#\#\#-UC-741, 1998.

35. Hobbs, M. L., Baer, M. R., and McGee, B. C., Eleventh International Detonation Symposium, Office of Naval Research, Arlington, VA, 1998, accepted for publication. 
Table 1. Repulsive force constants for an exponential 6 potential function

\begin{tabular}{|c|c|c|c|c|c|c|c|c|c|}
\hline Species & $\mathbf{r}^{*}, \AA$ & $\varepsilon / \mathbf{k}, \mathbf{K}$ & $\eta^{*}$ & Ref & Species & $\mathbf{r}^{*}, \AA$ & $\varepsilon / \mathrm{k}, \mathrm{K}$ & $\eta$ & Ref \\
\hline $\mathrm{Ar}$ & 3.83 & 119 & 15 & 13 & $\mathrm{HCl}$ & 4.14 & 262 & --- & 19 \\
\hline $\mathrm{Ar}$ & 3.85 & 122 & 13 & 11 & $\mathrm{HCO}_{2} \mathrm{H}$ & 4.15 & 463 & --- & 19 \\
\hline $\mathrm{Ar}$ & 3.93 & 120 & 12.9 & 14 & $\mathrm{He}$ & 3.14 & 9.16 & 12.4 & 17 \\
\hline C & 3.15 & 100 & --- & 15 & $\mathrm{HF}$ & 3.30 & 100 & --- & 16 \\
\hline $\mathrm{CF}_{4}$ & 5.00 & 220 & --- & 16 & $\mathrm{~F}_{2}$ & 3.50 & 200 & --- & 16 \\
\hline $\mathrm{CH}_{4}$ & 4.29 & 154 & 14 & 13 & $\mathrm{~N}_{2}$ & 4.05 & 120 & 15 & 13 \\
\hline $\mathrm{CH}_{4}$ & 4.22 & 154 & 13 & 11 & $\mathrm{~N}_{2}$ & 4.09 & 102 & 13 & 11 \\
\hline $\mathrm{CH}_{4}$ & 4.20 & 156 & 13.5 & 17 & $\mathrm{~N}_{2}$ & 4.11 & 117 & 13.5 & 17 \\
\hline $\mathrm{CH}_{4}$ & 4.39 & 136 & 12.2 & 14 & $\mathrm{~N}_{2}$ & 4.10 & 101 & 13.5 & 14 \\
\hline $\mathrm{Cl}_{2}$ & 4.61 & 337 & --- & 19 & $\mathrm{NF}_{3}$ & 4.10 & 200 & --- & 16 \\
\hline $\mathrm{CO}$ & 4.05 & 120 & 15 & 13 & $\mathrm{NH}_{3}$ & 3.35 & 138 & --- & 16 \\
\hline $\mathrm{CO}$ & 4.09 & 108 & 13 & 11 & $\mathrm{NH}_{3}$ & 4.15 & 154 & --- & 15 \\
\hline $\mathrm{CO}$ & 4.12 & 108 & 13 & 18 & $\mathrm{NH}_{3}$ & 3.44 & 474 & 13 & 18 \\
\hline $\mathrm{CO}_{2}$ & 4.20 & 200 & 15 & 13 & $\mathrm{NH}_{3}$ & 3.50 & 138 & 17 & 17 \\
\hline $\mathrm{CO}_{2}$ & 4.17 & 246 & 13 & 11 & $\mathrm{NH}_{3}$ & 4.00 & 200 & 11.2 & 14 \\
\hline $\mathrm{CO}_{2}$ & 4.21 & 249 & 13.8 & 14 & NO & 3.97 & 105 & 15 & 13 \\
\hline $\mathrm{H}_{2}$ & 3.34 & 37.0 & 14 & 13 & NO & 3.97 & 113 & 13 & 18 \\
\hline $\mathrm{H}_{2}$ & 3.43 & 36.4 & 11.1 & 18 & NO & 3.56 & 131 & -- & 15 \\
\hline $\mathrm{H}_{2}$ & 3.00 & 30 & 13.5 & 17 & NO & 3.9 & 105 & 12 & 17 \\
\hline $\mathrm{H}_{2}$ & 3.60 & 36.4 & 10.8 & 14 & $\mathrm{O}_{2}$ & 3.73 & 132 & 15 & 13 \\
\hline $\mathrm{H}_{2} \mathrm{O}$ & 3.35 & 138 & 14 & 13 & $\mathrm{O}_{2}$ & 3.84 & 125 & 13 & 11 \\
\hline $\mathrm{H}_{2} \mathrm{O}$ & 3.06 & 356 & 13 & 18 & $\mathrm{O}_{2}$ & 3.93 & 133 & 12.6 & 14 \\
\hline $\mathrm{H}_{2} \mathrm{O}$ & 3.37 & 135 & 13.5 & 17 & $\mathrm{Xe}$ & 4.47 & 235 & 13 & 11 \\
\hline $\mathrm{H}_{2} \mathrm{O}$ & 3.68 & 300 & 10.3 & 14 & $\mathrm{Xe}$ & 4.45 & 231 & 13 & 17 \\
\hline
\end{tabular}

* Fickett [13] uses 15 for $\eta$ and Ross and Ree [11] use 13 for $\eta$ when it has not been determined experimentally. Blank values for $\eta$ in this table have not been reported. 
Table 2. Predicted force constants using simple corresponding states and ELK

\begin{tabular}{|l|l|c|c|c|c|c|c|}
\hline \multicolumn{1}{|c|}{ Name } & Symbol & $\begin{array}{c}\mathbf{r}^{*}, \mathbf{\AA} \\
\mathbf{S c s}\end{array}$ & $\begin{array}{c}\boldsymbol{\varepsilon} / \mathbf{k}, \mathbf{K} \\
\mathbf{s c s}\end{array}$ & $\begin{array}{c}\mathbf{r}^{*}, \AA \\
\boldsymbol{\beta}\end{array}$ & $\begin{array}{c}\boldsymbol{\varepsilon} / \mathbf{k}, \mathbf{K} \\
\beta\end{array}$ & $\begin{array}{c}\mathbf{r}^{*}, \AA \\
\beta_{\mathbf{h}}\end{array}$ & $\begin{array}{c}\varepsilon / \mathbf{k}, \mathbf{K} \\
\beta_{\mathbf{h}}\end{array}$ \\
\hline \hline argon & $\mathrm{Ar}$ & 3.85 & 122 & 3.85 & 122 & 3.85 & 122 \\
\hline carbon tetrachloride & $\mathrm{CCl}_{4}$ & 5.95 & 450 & 5.98 & 631 & 5.98 & 631 \\
\hline chloroform & $\mathrm{CHCl}_{3}$ & 5.67 & 434 & 5.75 & 600 & 5.72 & 593 \\
\hline dibromomethane & $\mathrm{CH}_{2} \mathrm{Br}_{2}$ & 5.54 & 494 & 5.64 & 631 & 6.66 & 884 \\
\hline dichloromethane & $\mathrm{CH}_{2} \mathrm{Cl}_{2}$ & 5.20 & 413 & 5.00 & 459 & 5.11 & 484 \\
\hline diiodomethane & $\mathrm{CH}_{2} \mathrm{I}_{2}$ & 5.92 & 604 & 5.25 & 559 & 5.96 & 759 \\
\hline methanol & $\mathrm{CH}_{3} \mathrm{OH}$ & 4.48 & 415 & 3.96 & 333 & 3.59 & 240 \\
\hline methane & $\mathrm{CH}_{4}$ & 4.23 & 154 & 4.23 & 154 & 4.23 & 154 \\
\hline carbon dioxide & $\mathrm{CO}_{2}$ & 4.15 & 246 & 4.16 & 264 & 4.16 & 264 \\
\hline acetone & $\mathrm{C}_{3} \mathrm{H}_{6} \mathrm{O}$ & 5.42 & 411 & 5.02 & 441 & 5.16 & 472 \\
\hline hexane & $\mathrm{C}_{6} \mathrm{H}_{14}$ & 6.56 & 411 & 6.60 & 600 & 6.60 & 600 \\
\hline water & $\mathrm{H}_{2} \mathrm{O}$ & 3.52 & 523 & 3.06 & 356 & 3.06 & 356 \\
\hline nitrogen & $\mathrm{N}_{2}$ & 4.09 & 102 & 4.10 & 106 & 4.06 & 104 \\
\hline ammonia & $\mathrm{NH}_{3}$ & 3.81 & 328 & 3.42 & 254 & 3.47 & 268 \\
\hline oxygen & $\mathrm{O}_{2}$ & 3.82 & 125 & 3.83 & 131 & 3.83 & 131 \\
\hline xenon & $\mathrm{Xe}$ & 4.48 & 234 & 4.48 & 234 & 4.48 & 234 \\
\hline
\end{tabular}

* ses stands for simple-corresponding states theory. $\beta$ and $\beta_{h}$ indicate that the polar interactions were estimated using compressibilities and enthalpies, respectively. 
Table 3. Parameters required by ELK method for selected polar and nonpolar molecules

\begin{tabular}{|c|c|c|c|c|c|c|c|c|c|c|c|c|}
\hline Name & Symbol & $\begin{array}{l}\mathbf{T}_{\mathbf{c}} \\
\mathbf{K}\end{array}$ & $\begin{array}{c}\mathbf{P}_{\mathbf{c}} \\
\mathbf{a t m}\end{array}$ & $\begin{array}{c}\mathrm{V}_{\mathrm{c}} \\
\mathrm{cc} / \mathrm{mol}\end{array}$ & $\begin{array}{l}\mathbf{r} \\
\AA\end{array}$ & $\begin{array}{c}\rho \\
\mathrm{g} / \mathrm{cc}\end{array}$ & $\begin{array}{l}\mathbf{T}_{\mathbf{r}} \\
\mathbf{K}\end{array}$ & $\underset{\mathbf{a t m}}{\mathbf{P}_{\mathrm{r}}}$ & $\begin{array}{c}\mathbf{T}_{\mathbf{b p}} \\
\mathbf{K}\end{array}$ & $\alpha$ & $\beta$ & $\beta_{h}$ \\
\hline argon & $\mathrm{Ar}$ & 151 & 48 & 75 & 0 & 1.41 & 86 & 1.97 & 87 & -0.0008 & $0^{*}$ & 0 \\
\hline carbon tetrachloride & $\mathrm{CCl}_{4}$ & 556 & 45 & 276 & 3.46 & 1.58 & 298 & 1 & 350 & 0.2522 & 0 & 0 \\
\hline chloroform & $\mathrm{CHCl}_{3}$ & 536 & 54 & 239 & 3.18 & 1.49 & 293 & 1 & 334 & 0.2242 & -0.0665 & -0.0264 \\
\hline dibromomethane & $\mathrm{CH}_{2} \mathrm{Br}_{2}$ & 611 & 71 & 223 & 2.36 & 2.48 & 298 & 1 & 270 & 0.1479 & -0.1143 & -1.5322 \\
\hline dichloromethane & $\mathrm{CH}_{2} \mathrm{Cl}_{2}$ & 510 & 60 & 185 & 2.34 & 1.32 & 298 & 1 & 313 & 0.1463 & 0.3333 & 0.1667 \\
\hline diiodomethane & $\mathrm{CH}_{2} \mathrm{I}_{2}$ & 747 & 54 & 272 & 2.44 & 3.31 & 298 & 1 & 455 & 0.1548 & 0.895 & -0.0266 \\
\hline methanol & $\mathrm{CH}_{3} \mathrm{OH}$ & 513 & 80 & 118 & 1.54 & 0.79 & 293 & 1 & 338 & 0.0819 & 0.9086 & 1.5357 \\
\hline methane & $\mathrm{CH}_{4}$ & 191 & 46 & 99 & 0.023 & 0.43 & 112 & 1 & 112 & 0 & 0 & 0 \\
\hline carbon dioxide & $\mathrm{CO}_{2}$ & 304 & 73 & 94 & 0.99 & 0.78 & 293 & 10 & 195 & 0.0458 & 0 & 0 \\
\hline acetone & $\mathrm{C}_{3} \mathrm{H}_{6} \mathrm{O}$ & 508 & 46 & 209 & 2.74 & 0.79 & 293 & 1 & 329 & 0.1822 & 0.603 & 0.3961 \\
\hline hexane & $\mathrm{C}_{6} \mathrm{H}_{14}$ & 508 & 30 & 370 & 3.81 & 0.66 & 293 & 1 & 342 & 0.2885 & 0. & 0. \\
\hline water & $\mathrm{H}_{2} \mathrm{O}$ & 647 & 218 & 57 & 0.62 & 1.00 & 298 & 1 & 373 & 0.025 & 0.9997 & 0.9992 \\
\hline nitrogen & $\mathrm{N}_{2}$ & 126 & 34 & 90 & 0.55 & 0.81 & 77 & 1 & 78 & 0.0216 & -0.022 & 0.0518 \\
\hline ammonia & $\mathrm{NH}_{3}$ & 406 & 111 & 73 & 0.85 & 0.68 & 240 & 2 & 240 & 0.0378 & 0.7914 & 0.6787 \\
\hline oxygen & $\mathrm{O}_{2}$ & 155 & 50 & 73 & 0.68 & 1.14 & 90 & 1 & 90 & 0.0283 & 0 & 0 \\
\hline xenon & $\mathrm{Xe}$ & 290 & 58 & 118 & 0 & 2.95 & 165 & 1 & 165 & -0.0008 & 0 & 0 \\
\hline
\end{tabular}

$*$ Bs are zero for nonpolar molecules. 


\section{List of Figures}

Fig 1. Measured (symbols) and predicted (lines) pure shock Hugoniots: A) argon, B) methane, C) carbon dioxide, D) hydrogen, E) water, F) nitrogen. References shown in legend.

Fig 1. (Continued) Measured (symbols) and predicted (lines) pure shock Hugoniots: G) ammonia, H) oxygen, and I) xenon. References shown in legend.

Fig 2. Measured and JCZ3 predicted shock Hugoniot for n-hexane.

Fig 3. Measured (symbols) and JCZ3 predicted (lines) pure shock Hugoniots for $\mathrm{Ar}, \mathrm{CCl}_{4}$, $\mathrm{CHCl}_{3}, \mathrm{CBr}_{2} \mathrm{H}_{2}, \mathrm{CCl}_{2} \mathrm{H}_{2}, \mathrm{Cl}_{2} \mathrm{H}_{2}, \mathrm{CH}_{3} \mathrm{OH}$, and $\mathrm{CH}_{4}$ using simple corresponding states, the ELK method using $\beta$, and the ELK method using $\beta_{\mathrm{h}}$.

Fig 4. Measured (symbols) and JCZ3 predicted (lines) pure shock Hugoniots for $\mathrm{CO}_{2}, \mathrm{C}_{3} \mathrm{H}_{6} \mathrm{O}$, $\mathrm{C}_{6} \mathrm{H}_{14}, \mathrm{H}_{2} \mathrm{O}, \mathrm{N}_{2}, \mathrm{NH}_{3}, \mathrm{O}_{2}$, and $\mathrm{Xe}$ using simple corresponding states, the ELK method using $\beta$, and the ELK method using $\beta_{\mathrm{h}}$. 

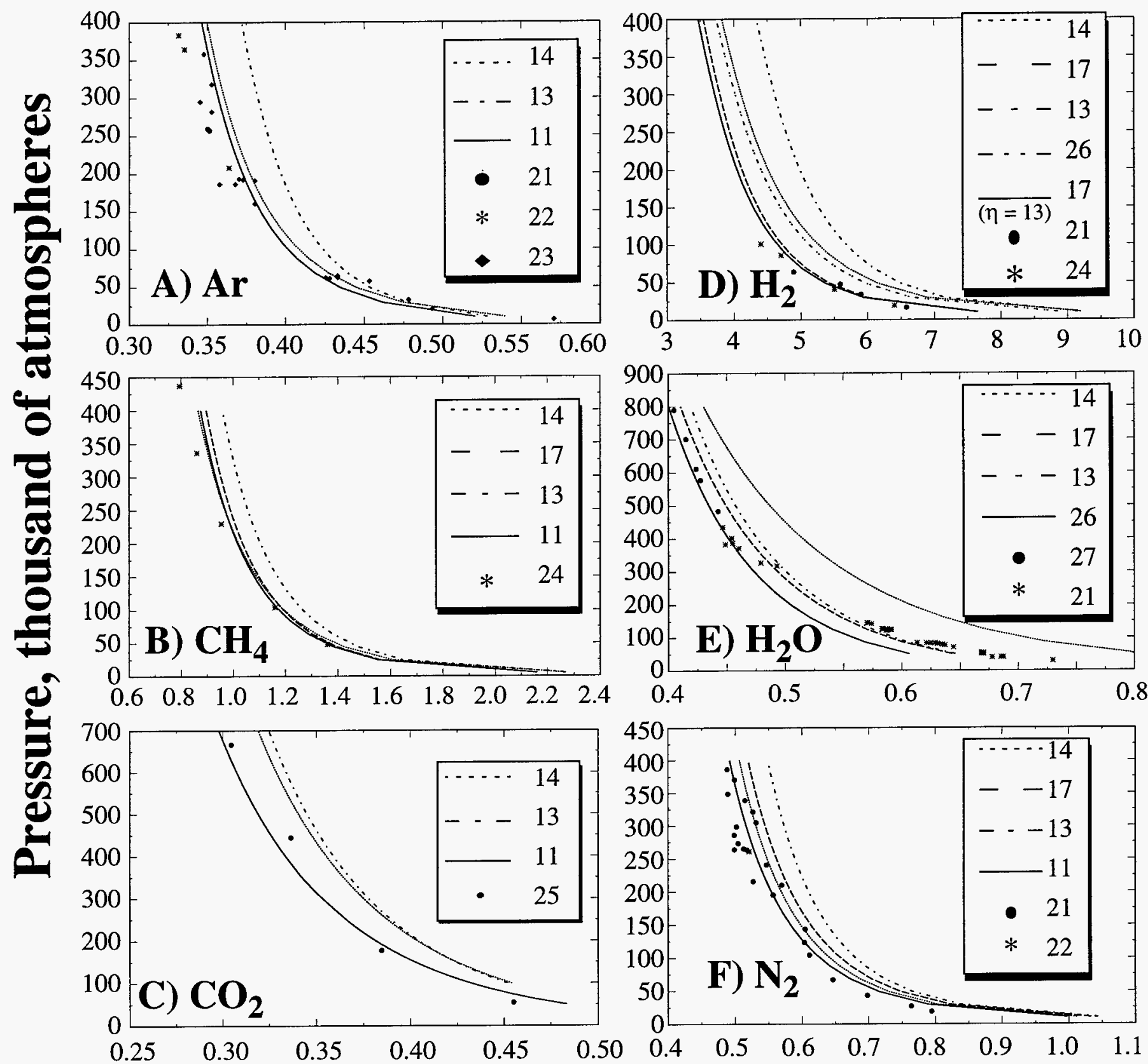

Volume, cc/g 


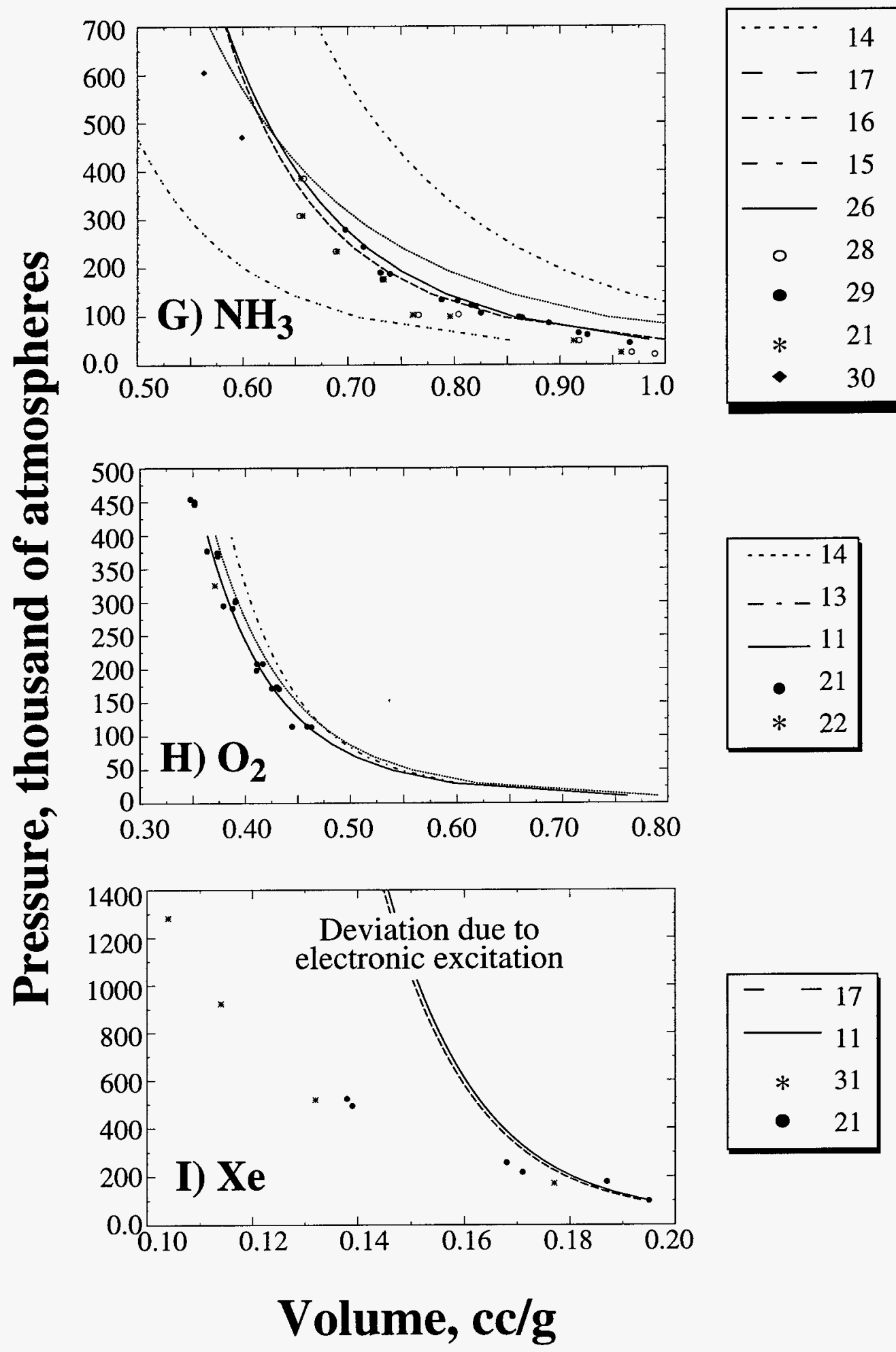




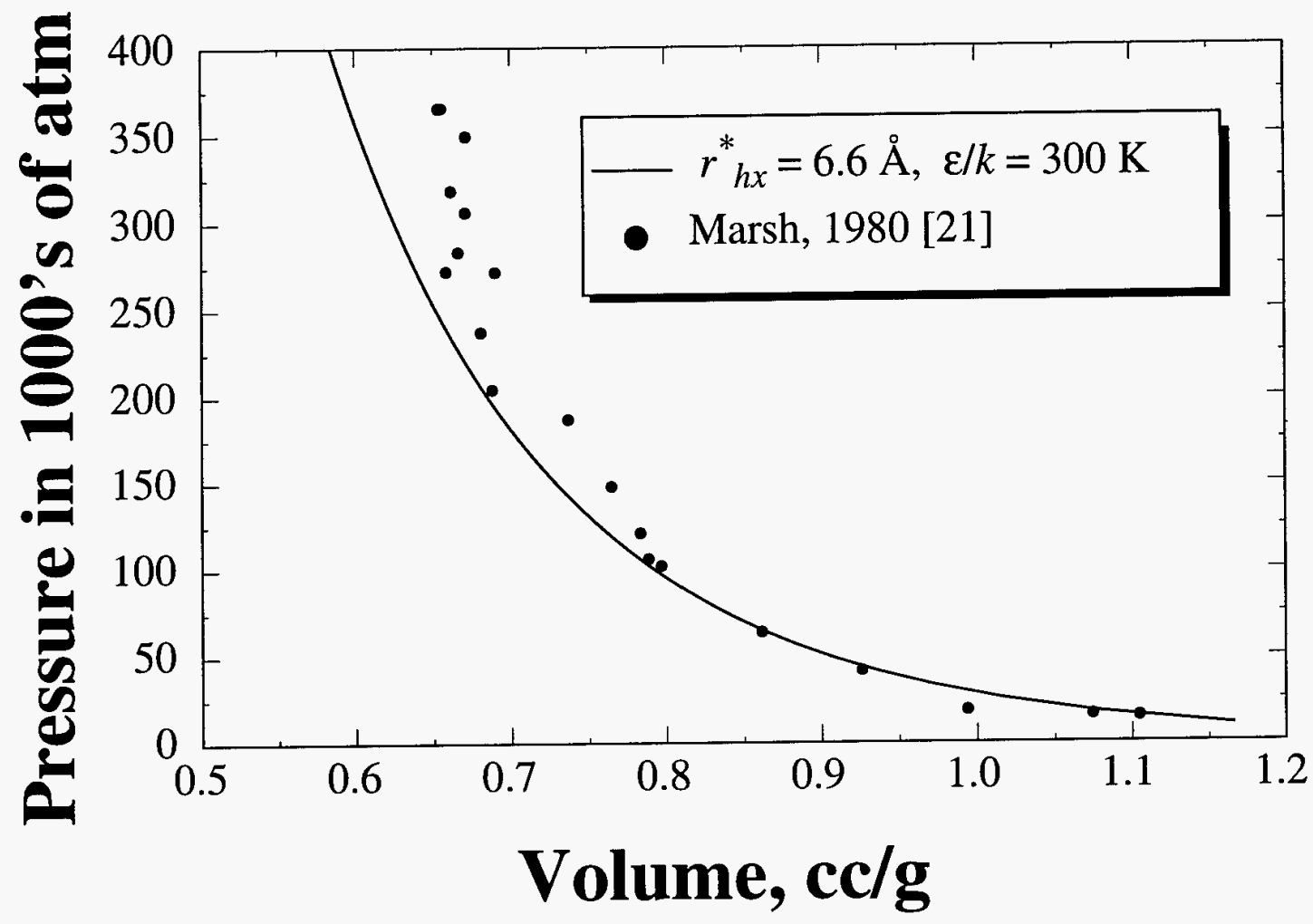




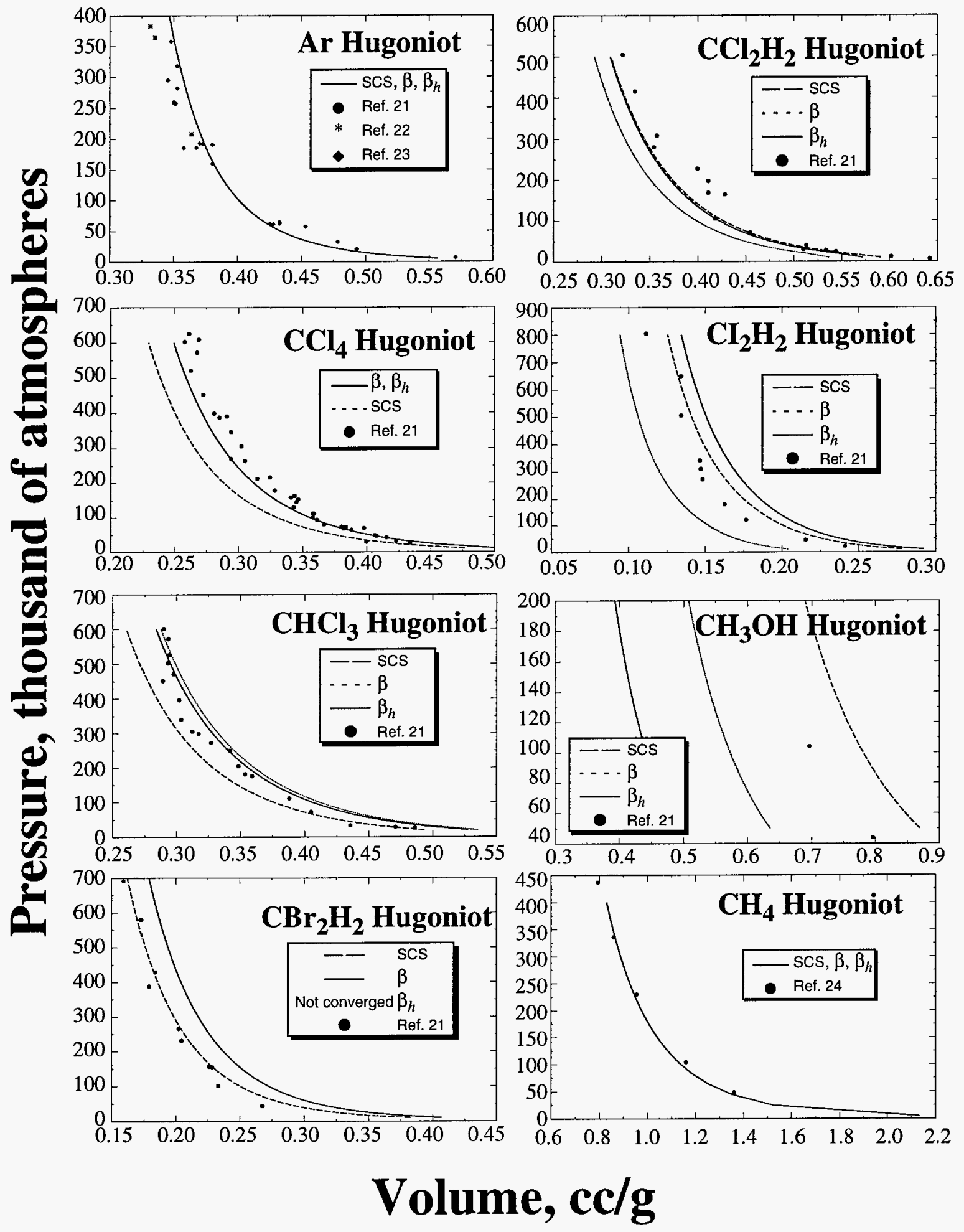




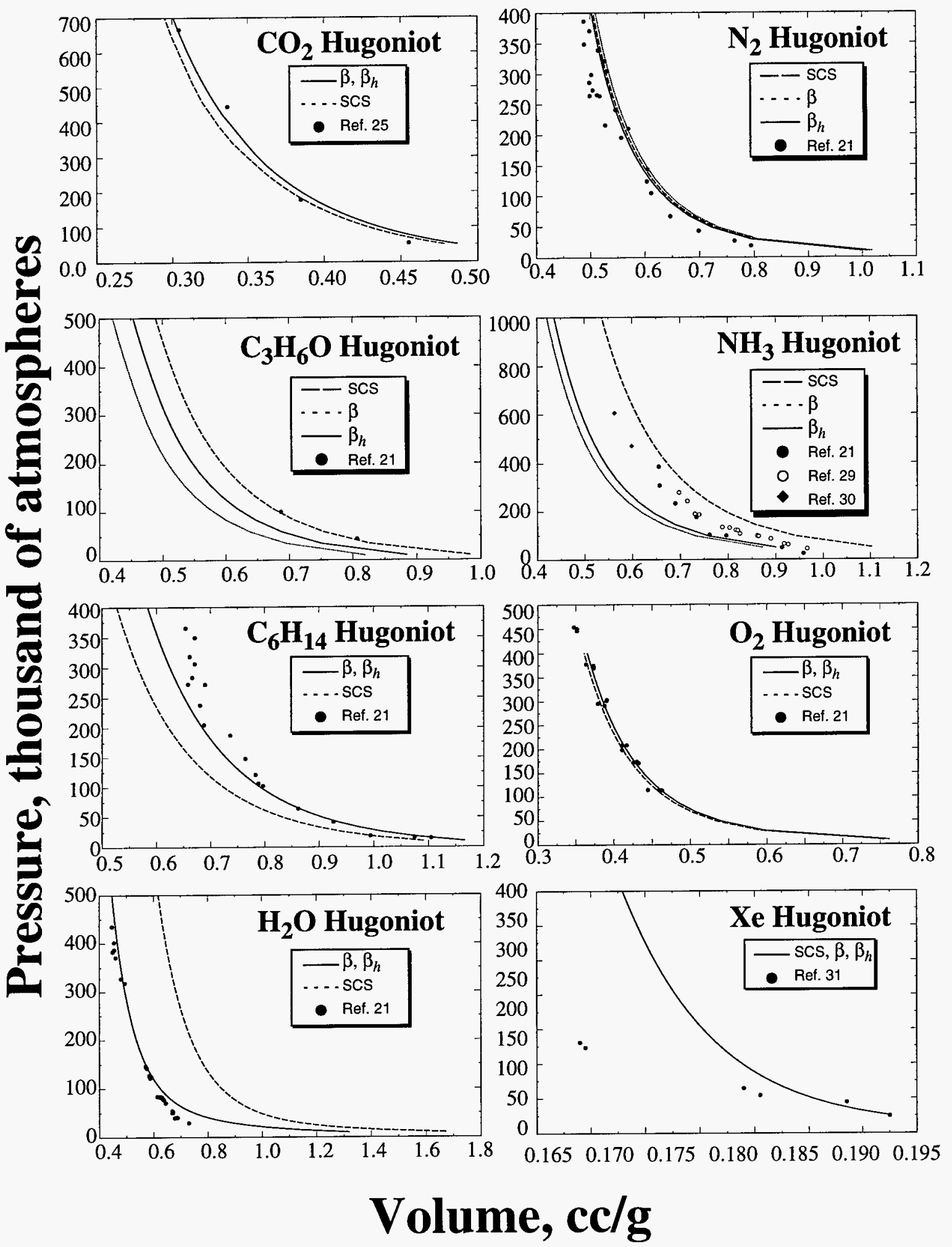


Report Number (14) SAND -.97-3/81C CONF-980804-.

Publ. Date (11) $\quad 1997 / 2$

Sponsor Code (18) DOE/DP, XE
UC Category (19) UC-700, DOE/ER 